\section{Effect of the Addition of Hand-Mixed Generic Vancomycin on Bone Cement Strength}

\section{Abstract}

Background: No literature up to date has investigated on the mechanical strength of hand-mixed Vancomycin cement spacers. This puts to question the reliability of such practice in creating the spacers for load support in addition to Methicillinresistant Staphylococcus aureus (MRSA) coverage.

Objective: The study compared the mechanical strength of hand-mixed generic Vancomycin bone cement with standard non-antibiotic bone cement.

Methods: One (1) gram vials of generic Vancomycin powder were dry-blended with the cement powder (Cemex) following standard aseptic hospital practice (1 $\mathrm{g}$ Vancomycin in $40 \mathrm{~g}$ of cement powder). Samples for the cement-alone group were done similarly except for the addition of the antibiotic powder. Tensile and compression samples were created, soaked in saline, and stored at 37 degrees Celsius for one week. All samples were tested at the University of the Philippines College of Engineering Mechanical Laboratory for compressive and tensile strength. Acceptance or rejection of the null hypothesis was conducted using the t-test procedure performed on Minitab 15 Trial Version, with $\alpha$ of 0.05 as the level of significance.

Results: T-test analysis performed on compressive strength data produced a p-value of 0.944 ( $\alpha$ of 0.05 ), and on tensile strength data, 0.311 ( $\alpha$ of 0.05 ).

Conclusion: There is no effect of the addition of hand-mixed generic Vancomycin on the mechanical properties of the bone cement.

Recommendation: Results indicate that mechanical properties of bone cement are not compromised by adding hand-mixed generic Vancomycin at the time of surgery, but limitations for treating established musculoskeletal MRSA infection were emphasized.

Keywords: Vancomycin, Methicillin-resistant Staphylococcus aureus, Bone cement

Received: October 31, 2015, Accepted: November 23, 2015, Published: December 02, 2015

\section{Mamer S. Rosario and Venancio P. Garduce}

\author{
Department of Orthopaedics, East \\ Avenue Medical Center, East Avenue, \\ Diliman, Quezon City, Philippines
}

Corresponding author: Mamer S. Rosario

mamerrosario@yahoo.com.ph

Department of Orthopaedics, East Avenue Medical Center, East Avenue, Diliman, Quezon City, Philippines

Tel: 639236863484

Citation: Rosario MS. Effect of the Addition of Hand-Mixed Generic Vancomycin on Bone Cement Strength. Ann Clin Lab Res. 2015, 3:4.

\section{Introduction}

The pioneers of joint replacement recognized the serious consequences of an infected arthroplasty and soon adopted the practice of incorporating antibiotics into acrylic bone cement. Antibiotic bone cement provides unique benefits not achieved through other forms of antibiotic administration. It provides local delivery of therapeutic levels while maintaining safe, nontoxic levels in the bloodstream [1,2]. It also allows for sustained delivery at the exact site most critical for preventing implant sepsis: the cement/bone interface. The homogeneous addition of up to $1 \mathrm{~g}$ of antibiotic does not interfere with the primary function of the cement, which is mechanical fixation of the prosthetic joint [3].

Although commercially prepared antibiotic bone cements have been available in international markets since the 1970s, some, 
like the commercially prepared Vancomycin with bone cement, are not available in most countries like the Philippines. In such countries where the product is unavailable, standard of care called for hand-mixing the powdered antibiotics into standard bone cement in the operating room at the time of surgery.

One of the greatest concerns of adding antibiotics by hand is the uncertainty in achieving a homogeneous mixture free of clumps, which may lead to weaker bone cement. Recently, it has been reported that hand-mixing generic Tobramycin (Pharma-Tek, Huntington, New York) into Simplex $\mathrm{P}$ bone cement results in a $36 \%$ decrease in the strength of the cement compared with the strength of commercially prepared Tobramycin-loaded bone cement (Simplex with Tobramycin; Stryker Orthopaedics) and that of plain Simplex P cement [4]. These findings are in direct contrast, however, to those of four previous studies in which the addition of Gentamicin powder into Palacos R bone cement (Smith and Nephew) [3,5], or either Erythromycin plus Colistin [6] or Tobramycin powder into Simplex $P$ bone cement [7] did not decrease the fatigue strength compared with that of the respective plain-cement controls. This was true whether or not the cement had been centrifuged.

Methicillin-resistant Staphylococcus aureus (MRSA) has been considered the most representative nosocomial pathogen since its pandemic waves over the past decades [8]. MRSA periprosthetic infections in the hospital have obviously imposed a high burden on healthcare resources as well as significant morbidity and mortality [9]. Particularly, some Asian countries like Korea, Japan, China, and Taiwan have been reported to show the highest rates of MRSA among S. aureus isolates from hospitals, reaching as high as $70-80 \%$ [10-13].

The proportion of MRSA among hospital-acquired (HA) S. aureus infections in the Philippines was reported by Song et al. [14] to be at $38.1 \%$. However, their data suggested the spread of MRSA between the community and hospitals in Asian countries, and found that MRSA has emerged as an important pathogen of community infections in many Asian countries including the Philippines, and are anticipating emergence of multi-drug resistant community-acquired MRSA strains in the region given the widespread endemicity of MRSA infections in most Asian hospitals and the possible spread of HA-MRSA strains to the community. These findings shall be alarming for all orthopedic surgeons in the region, in consideration of the very limited armamentarium we have for MRSA coverage.

In some countries like the Philippines where clinically-tested commercial cement with Vancomycin is not available, orthopedic surgeons tolerate the practice of hand-mixing Vancomycin and bone cement intra-operatively to create Vancomycin cement spacers. However, no literature up to date has investigated on the mechanical strength of hand-mixed Vancomycin cement spacers. This puts to question the reliability of such practice in creating the spacers for load support and avoiding implant loosening, in addition to MRSA coverage. Our biomechanical study shall help provide an answer to the question, and consequently, provide insights in the post-operative care and rehabilitation of patients who shall undergo surgery requiring such a spacer for MRSA coverage and structural support.
This study aims to compare the mechanical properties of handmixed bone cement with generic Vancomycin and non-antibiotic bone cement.

\section{Materials and Methods}

Bone cement powder (Cemex) was used in creating 20 samples each for the following 2 experimental groups: 1 ) the cement-alone group, and 2) the cement-plus-Vancomycin group. One gram vials of generic Vancomycin powder were used to create samples for the cement-plus-Vancomycin group. In each group, 10 samples were tested for compressive strength, and were created using a standard cylinder molder with dimensions as specified by the American Society for Testing and Materials (ASTM). The other 10 samples in each group were tested for tensile strength and also were created using a molder with dimensions according to the ASTM standard (Figure 1).

The samples were created in one of the operating rooms of the Lung Center of the Philippines (Quezon Avenue, Diliman, Quezon City). One gram vials of generic Vancomycin powder were dry-blended with the cement powder (1 g Vancomycin in $40 \mathrm{~g}$ of cement powder) following standard aseptic hospital practice, and mixed vigorously until a smooth-blend mixture of the cement and antibiotic was confidently achieved. Samples for the cement-alone group were done similarly except for the addition of the antibiotic powder. After mixing, ASTM-type tensile and compression samples were created using the appropriate standard molders. All samples were soaked in saline and stored at 37 degrees Celsius for one week, after which they were all tested at the University of the Philippines College of Engineering Mechanical Laboratory for compressive and tensile strength (Figures $\mathbf{2}$ and $\mathbf{3}$ ).

\section{Results}

Results of the compressive strength tests and tensile strength tests made on bone cement samples and bone cement mixed with Vancomycin are presented in the Tables $\mathbf{1}$ and $\mathbf{2}$.

\section{Analysis of Data}

\section{Model adequacy check}

The study calls for a comparison of two means, specifically the comparison of the mechanical strengths of bone cement samples alone and bone cement samples with hand-mixed generic Vancomycin. Model adequacy check should be done to validate the test statistics to be performed in the analysis of data. If the data from the experiments is normally distributed, analysis using T-test statistic is valid.

A T-test follows a normal probability distribution. A standard normal probability has a mean of zero and a standard deviation of 1 . To check for the normality of the data, normality test were conducted using Minitab 15 Trial Version wherein the normal probability plots were generated.

In a normal probability plot, normality of sample is checked visually using a fat pencil test. If the data falls along the straight line, the data is said to be normal. 


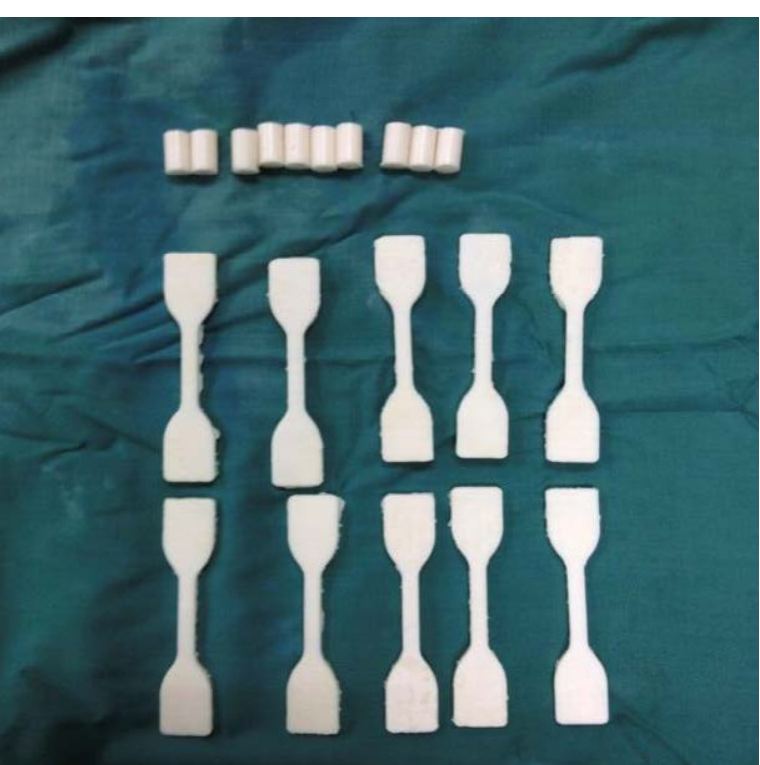

Figure 1 Compressive and tensile strength samples with ASTM standard dimensions.

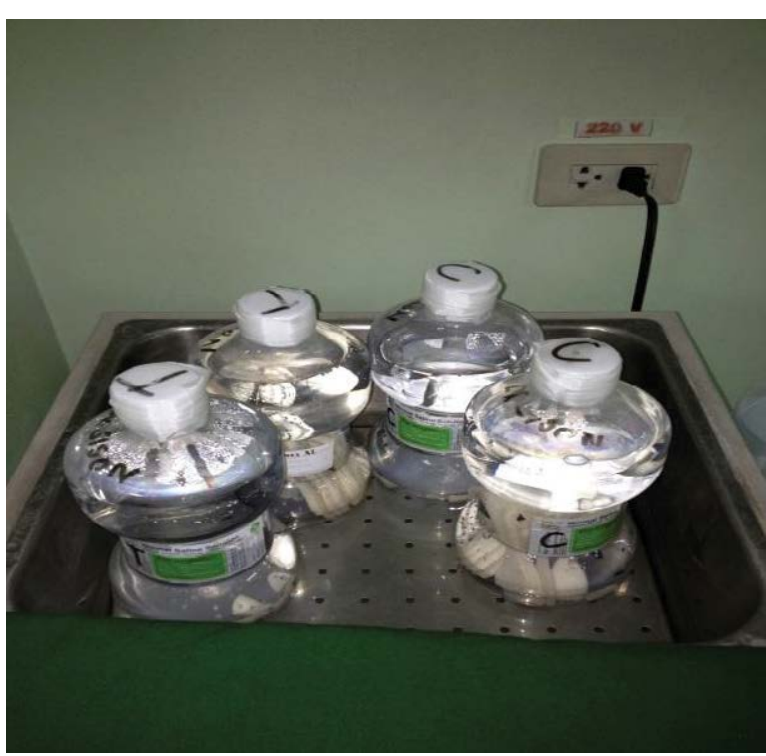

Figure 2 Saline-soaked samples stored at 37 degrees Celsius.

Figures 4-7 shows the probability plots per data set from Minitab 15 Trial Version. As seen from the figures, the data points are approximately normal, with no significant deviations from the straight line.

To further check for normality, analysis of variance was performed wherein the residuals were computed and residual probability plots were generated. Possible outliers were checked using the data from the analysis of variance as explained in the next section. Tables $\mathbf{3}$ and $\mathbf{4}$ show the computed residuals and the standardized residuals, while Figures $\mathbf{8}$ and $\mathbf{9}$ show the residual probability plots.

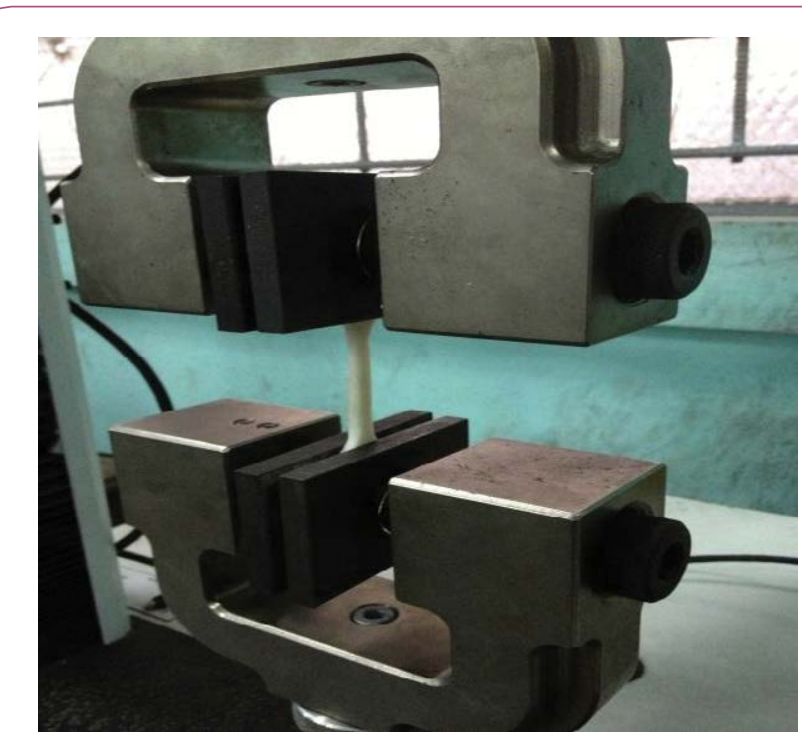

Figure 3 Tensile strength testing.

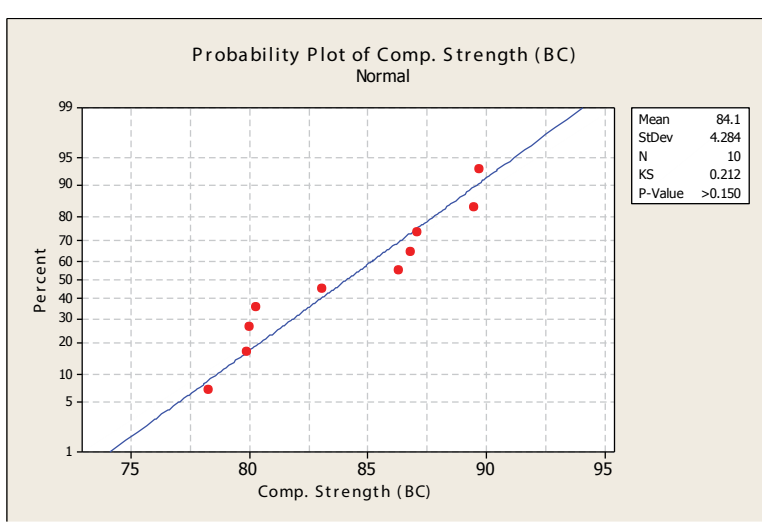

Figure 4 Tensil 4 Probability Plot of Compressive Strengths of Bone Cement. e strength testing.

\section{Check for outliers}

Values that deviate from the straight line in the normal probability plot may be a potential outlier. Investigation of the data should be done to detect the presence of outliers. One or more outliers can seriously affect the results of the analysis of variance. Oftentimes the cause of outliers is a mistake in calculations and data transfer or a mistake in the experimentation. Rejection of outliers must be carefully done unless we have reasonable non-statistical grounds for doing so.

Data points that are smaller and larger than then mean \pm the standard deviation are possible outliers. However with small samples, considerable fluctuations often occur, so the appearance of a moderate departure from normality does not necessarily imply a serious violation of the normality assumption (Montgomery, 2005).

Outliers from the data were checked by computing the standardized residuals, through the equation:

$d_{i j}=\frac{e_{i j}}{\sqrt{M S_{E}}}$ 
Table 1 Compressive Strength of Bone Cement and Bone Cement with Vancomycin.

\begin{tabular}{|c|c|c|}
\hline $\mathbf{k}$ & $\begin{array}{c}\text { Compressive Strength of } \\
\text { Bone Cement } \\
(\mathbf{k P a})\end{array}$ & $\begin{array}{c}\text { Compressive Strength } \\
\text { of Bone Cement } \\
\text { with Vancomycin (kPa) }\end{array}$ \\
\hline 1 & 89.7 & 80.5 \\
\hline 2 & 89.5 & 78.1 \\
\hline 3 & 83.1 & 86.3 \\
\hline 4 & 79.9 & 89.3 \\
\hline 5 & 78.3 & 85.7 \\
\hline 6 & 86.3 & 89.7 \\
\hline 7 & 80.3 & 82.4 \\
\hline 8 & 80.0 & 80.6 \\
\hline 10 & 87.1 & 84.6 \\
\hline Mean & 86.8 & 82.5 \\
\hline
\end{tabular}

Table 2 Tensile Strength of Bone Cement and Bone Cement with Vancomycin.

\begin{tabular}{|c|c|c|}
\hline$k$ & $\begin{array}{c}\text { Tensile Strength of Bone } \\
\text { Cement } \\
(\mathrm{kPa})\end{array}$ & $\begin{array}{c}\text { Tensile Strength } \\
\text { of Bone Cement } \\
\text { with Vancomycin(kPa) }\end{array}$ \\
\hline 1 & 17.3 & 18.7 \\
\hline 2 & 20.0 & 26.9 \\
\hline 3 & 14.9 & 18.7 \\
\hline 4 & 26.1 & 17.3 \\
\hline 5 & 17.6 & 28.5 \\
\hline 6 & 12.8 & 12.7 \\
\hline 7 & 12.9 & 13.8 \\
\hline 8 & 22.5 & 30.9 \\
\hline 10 & 23.8 & 15.9 \\
\hline Mean & 17.4 & 29.0 \\
\hline
\end{tabular}

Where dij is the standardized residual, eij is the error or residual, and $\mathrm{MS}_{\mathrm{E}}$ is the mean standard error. A residual bigger than 3 or 4 standard deviations from zero is a potential outlier [15].

One-way analysis of variance was performed to determine the residuals of the data points. Presented in Tables $\mathbf{3}$ and $\mathbf{4}$ are the corresponding residuals and standardized residuals of the compressive strengths and tensile strengths of bone cement samples and bone cement samples with Vancomycin.

Values of the standardized residuals in Tables $\mathbf{3}$ and $\mathbf{4}$ are lesser than 3 or 4 standard deviations from zero, thus we can assume that there are no outliers in the data.

\section{Hypothesis testing}

The study aims to compare the mechanical strength, specifically, the compressive and tensile strengths of bone cement alone and bone cement added with hand-mixed Vancomycin. A null hypothesis has been formulated that the addition of hand-mixed generic Vancomycin will not affect the mechanical strength of bone cement. On the other hand, an alternative hypothesis has been formulated as the exact opposite of the null hypothesis.

Acceptance or rejection of the null hypothesis is conducted using the T-Test procedure. A statistical analysis using T-Test was
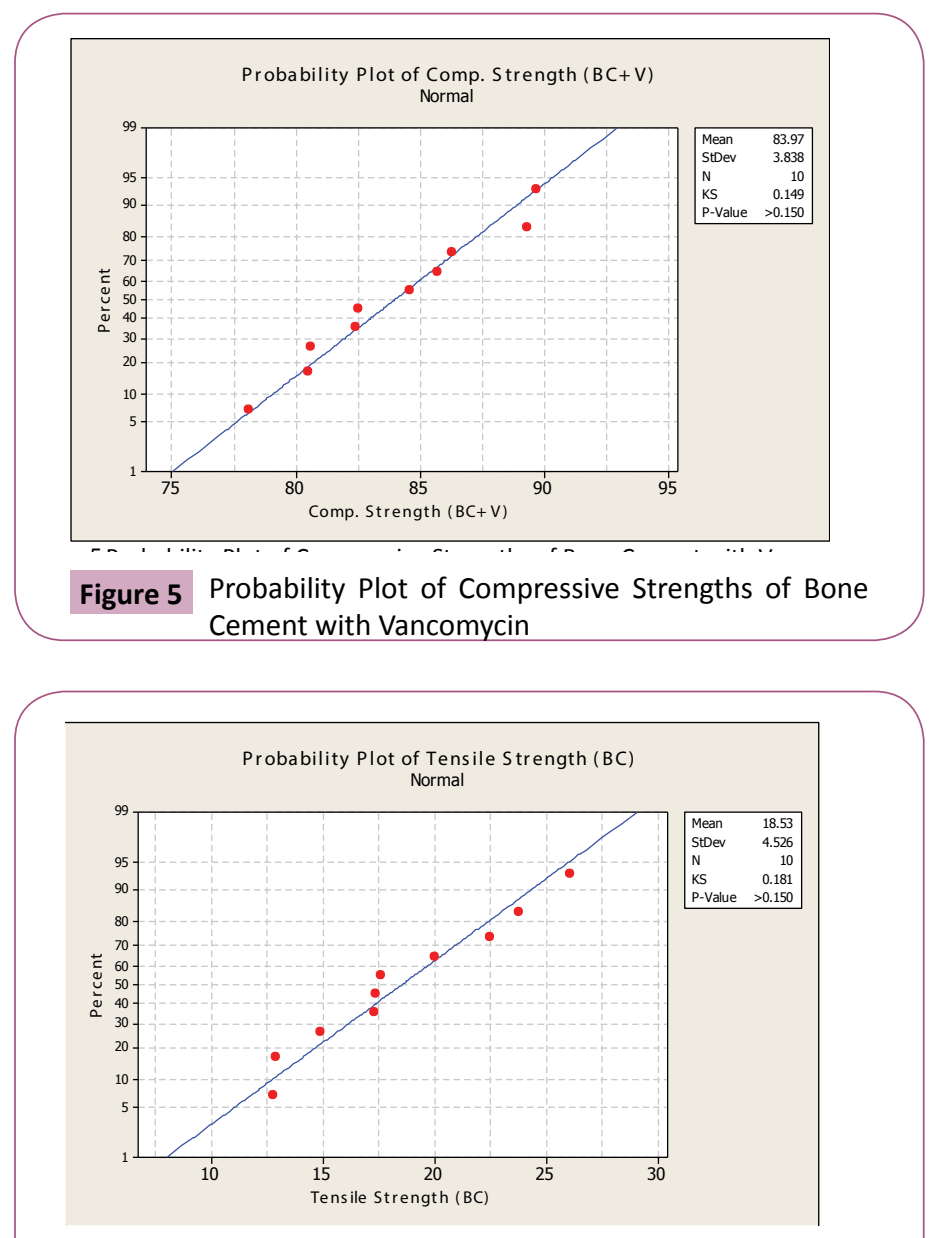

Figure 6 Probability Plot of Tensile Strengths of Bone Cement.

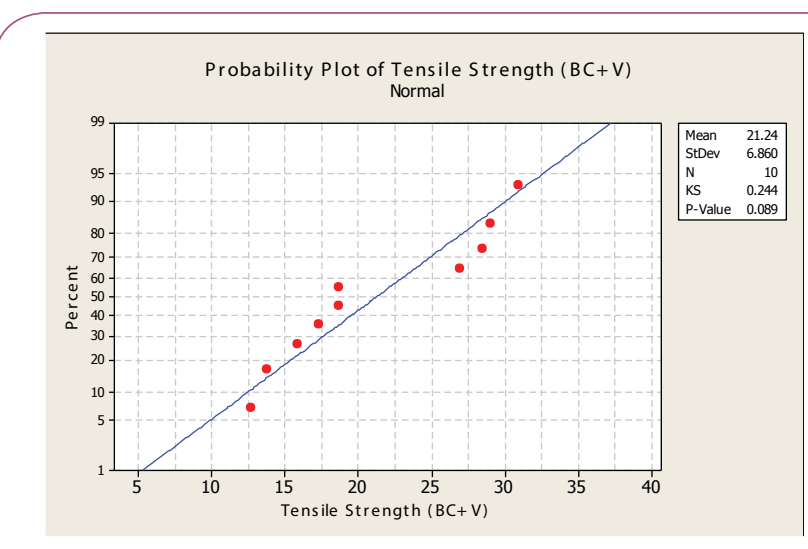

Figure 7 Probability Plot of Tensile Strengths of Bone Cement with Vancomycin.

performed on Minitab 15 Trial Version, with $\alpha$ of 0.05 as the level of significance. P-Value approach was used to test the null hypothesis. The P-Value is the smallest level of significance that would lead to the rejection of the null hypothesis. If the P-value is less than $\alpha$, then the null hypothesis shall be rejected.

T-test analysis performed on compressive strength data of bone cement samples alone and bone cement samples with handmixed Vancomycin produces a P-value of 0.944 , which is greater 
Table 3 Residuals and Standardized residuals of Compressive Strengths of Bone Cement Samples and Bone Cement Samples with Vancomycin.

\begin{tabular}{|c|c|c|c|c|c|}
$\begin{array}{c}\text { Compressive } \\
\begin{array}{c}\text { Strengths of Bone } \\
\text { Cement (KPa) }\end{array}\end{array}$ & $\begin{array}{c}\text { Compressive } \\
\text { Strengths of Bone } \\
\text { Cement with } \\
\text { Vancomycin (KPa) }\end{array}$ & $\begin{array}{c}\text { Residuals of } \\
\text { Compressive } \\
\text { Strengths of Bone } \\
\text { Cement }\end{array}$ & $\begin{array}{c}\text { Residuals of } \\
\text { Compressive } \\
\text { Strengths of Bone } \\
\text { Cement with } \\
\text { Vancomycin }\end{array}$ & $\begin{array}{c}\text { Standardized } \\
\text { Residuals of } \\
\text { Compressive } \\
\text { Strength of Bone } \\
\text { Cement }\end{array}$ & $\begin{array}{c}\text { Standardized Residuals of Compressive } \\
\text { Strengths of Bone Cement with } \\
\text { Vancomycin }\end{array}$ \\
\hline 89.7 & 80.5 & 5.6 & -3.47 & 1.38 & -0.85 \\
\hline 89.5 & 78.1 & 5.4 & -5.87 & 1.33 & -1.45 \\
\hline 83.1 & 86.3 & -1 & 2.33 & -0.25 & 0.57 \\
\hline 79.9 & 89.3 & -4.2 & 5.33 & -1.03 & 1.31 \\
\hline 86.3 & 85.7 & -5.8 & 1.73 & -1.43 & 0.43 \\
\hline 80.3 & 89.7 & 2.2 & 5.73 & 0.54 & 1.41 \\
\hline 87.1 & 82.4 & -3.8 & -1.57 & -0.94 & -0.39 \\
\hline
\end{tabular}

Table 4 Residuals and Standardized residuals of Tensile Strengths of Bone Cement Samples and Bone Cement Samples with Vancomycin.

\begin{tabular}{|c|c|c|c|c|c|}
\hline $\begin{array}{c}\text { Tensile Strengths } \\
\text { of Bone Cement } \\
\text { (KPa) }\end{array}$ & $\begin{array}{c}\text { Tensile Strengths } \\
\text { of Bone Cement } \\
\text { with Vancomycin } \\
\text { (KPa) }\end{array}$ & $\begin{array}{c}\text { Residuals of } \\
\text { Tensile Strengths } \\
\text { of Bone Cement }\end{array}$ & $\begin{array}{c}\text { Residuals of } \\
\text { Tensile Strengths } \\
\text { of Bone Cement } \\
\text { with Vancomycin }\end{array}$ & $\begin{array}{c}\text { Standardized } \\
\text { Residuals of Tensile } \\
\text { Strength of Bone } \\
\text { Cement }\end{array}$ & $\begin{array}{c}\text { Standardized Residuals of Tensile } \\
\text { Strengths of Bone Cement with } \\
\text { Vancomycin }\end{array}$ \\
\hline 17.3 & 18.7 & -1.23 & -2.54 & -0.21 & -0.44 \\
\hline 20.0 & 26.9 & 1.47 & 5.66 & 0.25 & 0.97 \\
\hline 14.9 & 18.7 & -3.63 & -2.54 & -0.62 & -0.44 \\
\hline 26.1 & 17.3 & 7.57 & -3.94 & 1.30 & -0.68 \\
\hline 17.6 & 28.5 & -0.93 & 7.26 & -0.16 & 1.25 \\
\hline 12.8 & 12.7 & -5.73 & -8.54 & -0.99 & -1.47 \\
\hline 12.9 & 13.8 & -5.63 & -7.44 & -0.97 & -1.28 \\
\hline 22.5 & 30.9 & 3.97 & 9.66 & 0.68 & 1.66 \\
\hline 23.8 & 15.9 & 5.27 & -5.34 & 0.91 & -0.92 \\
\hline 17.4 & 29.0 & -1.13 & 7.76 & -0.19 & 1.33 \\
\hline
\end{tabular}

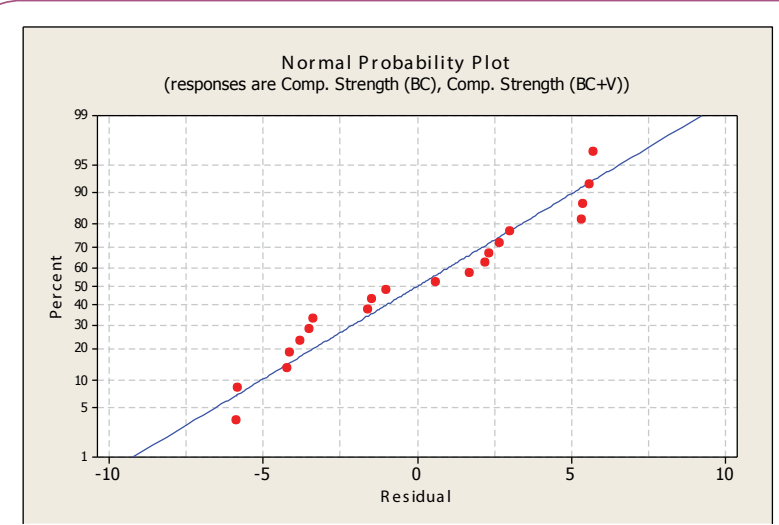

Figure 8 Residual Probability Plot of Compressive Strengths of Bone Cement and Bone Cement with Hand-Mixed Vancomycin.

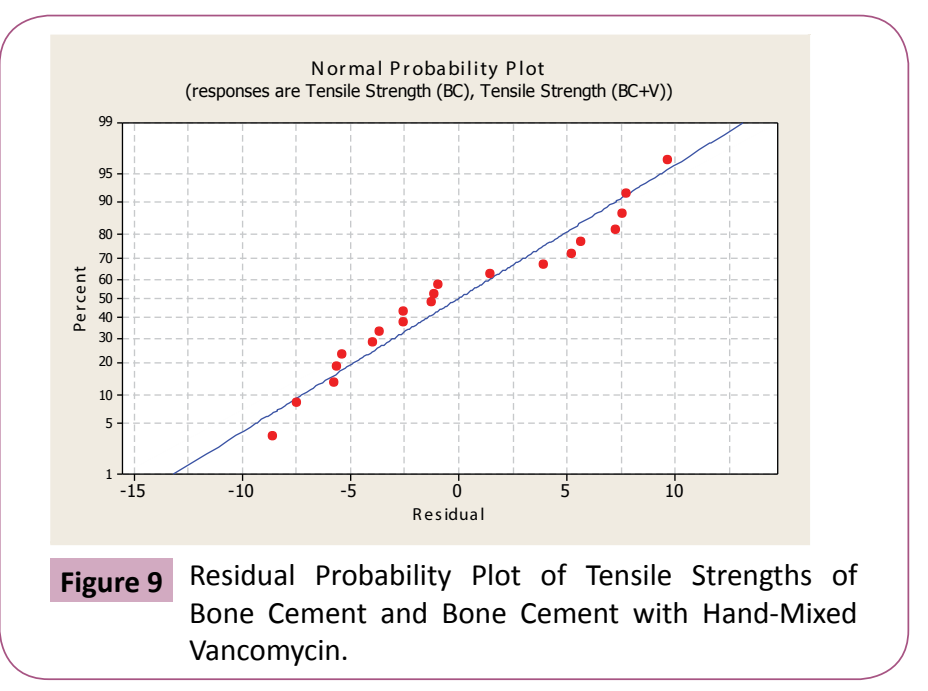


than the level of significance $\alpha$-value of 0.05 . The null hypothesis for tensile strength is accepted. It can be said that the addition of hand-mixed generic Vancomycin has no effect on the compressive strength of bone cement.

T-test analysis performed on tensile strength data of bone cement samples alone and bone cement samples with handmixed Vancomycin produces a P-value of 0.311 , which is greater than the level of significance $\alpha$-value of 0.05 . The null hypothesis for tensile strength is likewise accepted. It can also be said that the addition of hand-mixed generic Vancomycin has no effect on the tensile strength of bone cement.

Therefore, based on the statistical analyses performed on results of the compressive and tensile strengths tests of bone cement and bone cement with hand-mixed Vancomycin, there is no effect of the addition of hand-mixed Vancomycin on the mechanical properties of the bone cement.

\section{Discussion}

Results show that adding hand-mixed generic Vancomycin does not decrease the mechanical performance of bone cement. These findings support such practice for making Vancomycin bone cement for purposes of achieving load support in addition to MRSA coverage. But it must be emphasized that what was used in this study are low-dose antibiotic-loaded bone cement samples, and therefore, if to be used for MRSA coverage, can only be for prophylaxis and not treatment.

It has been shown that at least 3.6 gms of antibiotic per $40 \mathrm{~g}$ of acrylic cement is desirable for effective elution kinetics and sustained therapeutic levels of antibiotic. Doses as high as 6 to $8 \mathrm{~g}$ of antibiotic per 40-g batch of bone cement, when antibioticloaded bone cement is used in the form of beads or spacers, have been shown to be safe clinically. The use of this high dose is important for the sustained elution of antibiotics at levels that are therapeutic for the pathogenic organisms being treated.

In contrast with treatment, prophylaxis requires low doses of antibiotics in the bone cement to avoid adverse mechanical effects on cement that is intended for mechanical fixation of an implant. In general, low-dose antibiotic-loaded bone cement is defined as less than or equal to $1 \mathrm{gm}$ of powdered antibiotic per $40 \mathrm{~g}$ of bone cement. Numerous in-vitro studies of bone cement have demonstrated a theoretical mechanical disadvantage of high-dose antibiotic-loaded bone cement $[4,16,17]$. To date, clinical studies have not shown an increase in the mechanical loosening rate with the use of low-dose antibiotic-loaded bone cement.

Since the antibiotic-loaded bone cement samples used in this study are low-dosed, the findings of this study are not appropriate for the construction of cement spacers or beads for the treatment of an established musculoskeletal infection. 


\section{References}

1 Sterling GJ, Crawford S, Potter JH, Koerbin G, Crawford R (2003) The pharmacokinetics of Simplex-tobramycin bone cement. J Bone Joint Surg $\mathrm{Br}$ 85: 646-649.

2 Brien WW, Salvati EA, Klein R, Brause B, Stern S (1993) Antibiotic impregnated bone cement in total hip arthroplasty. An in vivo comparison of the elution properties of tobramycin and vancomycin. Clin Orthop Relat Res: 242-248.

3 Davies JP, Harris WH (1991) Effect of hand mixing tobramycin on the fatigue strength of Simplex P. J Biomed Mater Res 25: 1409-1414.

4 Deluise M, Scott CP (2004) Addition of hand-blended generic tobramycin in bone cement: effect on mechanical strength. Orthopedics 27: 1289-1291.

5 Davies JP, O'Connor DO, Burke DW, Harris WH (1989) Influence of antibiotic impregnation on the fatigue life of Simplex $\mathrm{P}$ and Palacos $\mathrm{R}$ acrylic bone cements, with and without centrifugation. J Biomed Mater Res 23: 379-397.

6 Best AJ, Fender D, Harper WM, McCaskie AW, Oliver K, et al. (1998) Current practice in primary total hip replacement: results from the National Hip Replacement Outcome Project. Ann R Coll Surg Engl 80 : 350-355.

7 Buchholz HW, Elson RA, Engelbrecht E, Lodenkämper H, Röttger J, et al. (1981) Management of deep infection of total hip replacement. J Bone Joint Surg Br 63-63B: 342-53.

8 DeLeo FR, Chambers HF (2009) Reemergence of antibiotic-resistant Staphylococcus aureus in the genomics era. J Clin Invest 119: 2464 2474.
9 Boucher HW, Corey GR (2008) Epidemiology of methicillin-resistant Staphylococcus aureus. Clin Infect Dis 46 Suppl 5: S344-349.

10 Lee K, Chang CL, Lee NY, Kim HS, Hong KS, et al. (2000) Korean Nationwide Surveillance of Antimicrobial Resistance of Bacteria in 1998. Yonsei Med J 41: 497-506.

11 Boyce JM, Cookson B, Christiansen K, Hori S, Vuopio-Varkila J, et al. (2005) Meticillin-resistant Staphylococcus aureus. Lancet Infect Dis 5: 653-663.

12 Aires de Sousa M, Crisóstomo MI, Sanches IS, Wu JS, Fuzhong J, et al. (2003) Frequent recovery of a single clonal type of multidrugresistant Staphylococcus aureus from patients in two hospitals in Taiwan and China. J Clin Microbiol 41: 159-163.

13 Voss A, Doebbeling BN (1995) The worldwide prevalence of methicillin-resistant Staphylococcus aureus. Int J Antimicrob Agents 5: 101-106.

14 Song JH, Hsueh PR, Chung DR, Ko KS, Kang Cl, et al. (2011) Spread of methicillin-resistant Staphylococcus aureus between the community and the hospitals in Asian countries: an ANSORP study. J Antimicrob Chemother 66: 1061-1069.

15 Montgomery D (2005) Design and Analysis of Experiments. (6thedn.) Hoboken, NJ: Wiley.

16 Moran JM, Greenwald AS, Matejczyk MB (1979) Effect of gentamicin on shear and interface strengths of bone cement. Clin Orthop Relat Res 96-101.

17 Seldes RM, Winiarsky R, Jordan LC, Baldini T, Brause B, et al. (2005) Liquid gentamicin in bone cement: a laboratory study of a potentially more cost-effective cement spacer. J Bone Joint Surg Am 87: 268-272. 